\title{
Research on Higher Mathematics Teaching Practice Based on Curriculum Ideological and Political Education
}

\author{
Nan Wang ${ }^{1, *}$ Linjing Yan $^{2}$ Yu Wang ${ }^{3}$ \\ ${ }^{1,2,3}$ Fundamental Education College, Beijing Polytechnic, Beijing, China \\ *Corresponding author. Email:85454456@qq.com
}

\begin{abstract}
Curriculum ideological and political education is a comprehensive educational concept that takes "Building Morality and cultivating people" as the fundamental task of education. How to properly integrate the ideological and political education into the curriculum in the higher mathematics classroom is an important topic to be studied. According to the characteristics of students, this paper fully explores the ideological education elements contained in higher mathematics courses, naturally integrates them into classroom teaching links, and puts forward ideas, so as to finally realize the organic integration and unity of Ideological and political education and knowledge system education.
\end{abstract}

Keywords: Curriculum ideological and Political Education, Higher mathematics, Teaching practice.

\section{INTRODUCTION}

Curriculum ideological and political education aims at "combining knowledge transfer with value guidance" and integrating the fundamental task of Building Morality and cultivating people in Colleges and universities into all links and elements of curriculum teaching. Higher mathematics course is one of the most important basic theoretical courses in higher vocational education. Classroom teaching is the most important way to cultivate students' quality and ability. As a mathematics teacher in higher vocational colleges, it is the top priority to combine the education of correct world outlook, values and methods with the cultivation of scientific spirit to students.

In the course of higher mathematics, we should constantly explore the appropriate "Ideological and political points" and naturally integrate them into the classroom teaching process, so as to improve students' Ideological and political literacy and improve their ability to correctly understand, analyze and solve problems.

\section{WE SHOULD UNDERSTAND THE CHARACTERISTICS OF STUDENTS' IDEOLOGICAL AND POLITICAL LEARNING}

Higher mathematics is an important compulsory basic course. The students are freshmen who have just changed from basic education to higher education. These students are in the transition period from youth to adulthood. The physical age of students determines that they are in a special growth period with the coexistence of independent consciousness and rebellious psychology. They often doubt, doubt or even reject the positive values education.

With the growth of age, the pressure of society and employment is also slowly increasing, which will make some students have utilitarian thoughts to a certain extent, pay more attention to the learning of professional knowledge and the improvement of professional skills, simply take learning as a means of survival after graduation, and have insufficient enthusiasm for values education.

In today's Internet big data era, the rise of network culture has a great impact on the values of some students, making it more difficult for students to judge the right and wrong of value [1].

In this context, it is particularly important for students to establish a positive and healthy outlook on life and values. Higher mathematics teachers should better integrate mathematical knowledge and moral education elements, and have a positive influence on the freshmen who have just entered the school, so as to help 
them better study the future courses, maintain a healthy and upward attitude, and become the talents really needed by the society.

\section{WE SHOULD IMPROVE THE IDEOLOGICAL AND POLITICAL QUALITY OF COLLEGE TEACHERS}

In the traditional classroom teaching of higher mathematics, teachers generally pay attention to the academic education of theoretical teaching and ignore the quality education of ideological education, moral education and humanistic education. The advanced mathematics classroom integrated into the course of Ideological and political education should not only talk about concepts, formulas, proofs and calculations, but also teach students the humanistic cognition and philosophical speculation of the discipline, so as to help students establish a correct world outlook and values.

College teachers shoulder the mission of educating people, not only imparting knowledge, but also inheriting ideology and morality [2]. Teachers themselves should strengthen theoretical study, care about current affairs and politics, and improve their ideological and political cultivation, so as to be a good guide for students.

\section{HOW TO FULLY EXPLORE THE IDEOLOGICAL AND POLITICAL ELEMENTS OF HIGHER VOCATIONAL MATHEMATICS}

Higher mathematics has a long history and culture. Its concepts, theorems, properties and symbols are closely related to our daily life [3]. There is room to fully explore the ideological and political elements.

To fully explore the ideological and political elements of higher vocational mathematics, we should start from the following aspects:

\subsection{The history of mathematics is excavated as an ideological and political element.}

The research of any discipline is inseparable from the relevant historical background, historical culture and historical figures. It is necessary to integrate the stories of mathematicians and the history of mathematics into classroom teaching as ideological and political elements in combination with the teaching content, which can enrich students' mathematical history and cultural knowledge, stimulate students' admiration for mathematicians' exploration spirit, and improve their interest in mathematics learning and enthusiasm for mathematics research.

\subsection{Explore the application cases in daily life as ideological and political elements.}

Life is inseparable from mathematics. There is mathematics everywhere in life. Taking examples in life as ideological and political elements can shorten the distance between higher mathematics knowledge and students, make students learn for use, not for learning, and stimulate students' exploration spirit of mathematics learning.

\subsection{The discipline characteristics of higher mathematics are regarded as ideological and political elements.}

As a basic science, higher mathematics has its inherent characteristics, which are high abstraction, strict logic and wide application. Many mathematical definitions and formulas are summarized from specific objective phenomena. Taking the formation process of mathematical knowledge as the ideological and political point can not only strengthen students' understanding of definitions and training of formulas, but also cultivate students' dialectical thinking and improve students' materialist and dialectical views.

\section{HOW TO EFFECTIVELY IMPLEMENT THE CURRICULUM OF IDEOLOGICAL AND POLITICAL EDUCATION}

The integration of curriculum and ideological and political education should be silent. First, let students think that the ideological and political elements of the curriculum should be a part of the curriculum and should be naturally integrated, rather than being added, mechanically copied and forcibly implanted. Then it can effectively arouse students' emotional resonance, so as to achieve the purpose of Ideological and political education. Finally, in the experience, it can effectively stimulate students' internal motivation to learn, and promote students' understanding, mastery, expansion and deepening of curriculum knowledge.

How to make the course of Ideological and political education naturally run through the classroom teaching, this paper studies the ideological and political classroom teaching process taking lobida's law in higher mathematics as an example:

\subsection{Before class: introduction of Ideological and Political Education}

L'Hospital took John Bernoulli as his teacher and bought the research results from Bernoulli, who was in financial difficulties at that time, L'Hospital put forward the famous algorithm "L'Hospital's rule". Until the death of L'Hospital, Bernoulli said that he was the real founder, but it was questioned by people. Nowadays, 
few mathematical books call the law "Bernoulli's rule", and people are still used to calling it " L'Hospital's rule ". This may be the most regretful thing in Bernoulli's life. [4].

Through the story of "the real founder of L'Hospital's rule ", students should understand that they should have a correct view of the purpose, value and significance of human survival and a correct judgment of the value of things. We can't betray morality and conscience for interests. Only down-to-earth work and life are the real meaning of life. Lead students to establish a correct world outlook, outlook on life and values.

\subsection{In class: Ideological and political education runs through the teaching process}

As the noble spirit of human civilization, scientific spirit expresses the courage to adhere to scientific thought and the consciousness of constantly seeking truth. The spirit of exploration and innovation are the most important connotation and characteristics of scientific spirit.

Through the process of solving limit problems with derivative as a tool, let students understand that exploration and innovation are the vitality of scientific spirit [5]. If you encounter various problems in your study, you should find ways to solve them with the scientific spirit of bold exploration, exploration and innovation. When you encounter various difficulties in life, you should also face them bravely and actively find ways to solve them.

The method to solve other types of indefinite limits is to use L'Hospital's rule after appropriate transformation. In terms of knowledge, let students extend the difficulty and depth of knowledge on the basis of mastering basic knowledge and methods, and broaden students' cognitive breadth and problem-solving skills; Ideologically, more in-depth cultivation of students' scientific spirit of being good at thinking, diligent in thinking, bold in exploration and continuous innovation.

\subsection{End of class: summary and Reflection on Ideological and political education of the course}

Mathematics pays attention to preciseness, there are chapters in operation research, methods in calculation, and justifications. People are always required not to violate the scientific laws of mathematics. When applying L'Hospital's rule, we must find out the conditions of the theorem and use it according to the rules. This is also the principle of being a man and doing things - individual activities should be carried out within the scope of rules and laws. By examining the conditions for the use of theorems, we can constantly cultivate students' rigorous learning style and dedicated learning habits. Deeply understand that there are rules for calculation, laws and regulations in society, and it is impossible to form a circle without rules. Enhance the awareness of rules, integrity and discipline, consciously stay under the rules and abide by the rules.

\section{CONCLUSIONS}

Based on the analysis of the students' characteristics and the improvement of college teachers' Ideological and political literacy, this paper puts forward the angles and methods of how to excavate the elements of curriculum ideological and political education, and practices the application of curriculum ideological and political education in teaching with examples.

The goal of ideological and political education in curriculum is to impart students' curriculum knowledge and establish correct values [6]. Curriculum ideological and political education should not only make students "move with emotion" from emotion, but also "tell with reason" from knowledge, so as to achieve better educational effect.

As an important basic course in colleges, higher mathematics should not only pay attention to the training of scientific thinking methods and the education of scientific ethics, but also cultivate students' sense of responsibility and mission to explore the unknown, pursue the truth and climb the peak of science. We should also pay attention to professional ethics education, cultivating students' national advanced skills worker 'spirit of Excellence, and inspire students' feelings of home and country and mission of serving the country through science and technology.

\section{REFERENCES}

[1] Integrating the thought of dialectical materialism into the ideological and political education of Higher Mathematics Curriculum [J]. Modern vocational education, Wang song, Wang Xiaoming. 2019(02)

[2] Discussion on Ideological and political teaching of linear programming course $[\mathrm{J}]$. Higher Education Forum, Xin Wenfang, 2020.5.20

[3] Cases of moral education infiltration in mathematical modeling teaching in Higher Vocational Colleges [J]. Modern vocational education, Xiao Qianjun, Deng Zonggang, Shi Shuanglong, 2020(33)

[4] Advanced mathematics [M]. Beijing Normal University Press, Wang Jiaxin, Wang Jianrong,2020.09 
[5] Case teaching practice of "Ideological and political course" in Higher Mathematics -- Taking "separable variable equation" as an example [J]. teacher, Wu ye, 2020 (20)

[6] On the effective path of Ideological and political orientation of higher mathematics courses in Applied Technology Universities [J]. Scientific literature collection, Wei zhue, He Jiawen,2019.02 